March 2002 - NREL/SR-620-31620

\title{
Value of Distributed Energy Options for Congested Transmission/Distribution Systems in the Southeastern United States: Mississippi and Florida Case Studies
}

\section{January 1999-December 2001}

S.A. McCusker and J.S. Siegel Energy Resources International, Inc. Washington, $D C$

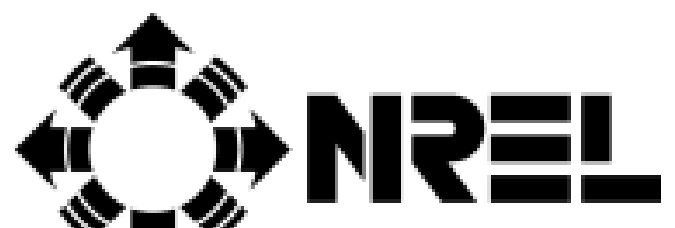

National Renewable Energy Laboratory

1617 Cole Boulevard

Golden, Colorado 80401-3393

NREL is a U.S. Department of Energy Laboratory

Operated by Midwest Research Institute $\bullet$ Battelle $\bullet$ Bechtel

Contract No. DE-AC36-99-G010337 


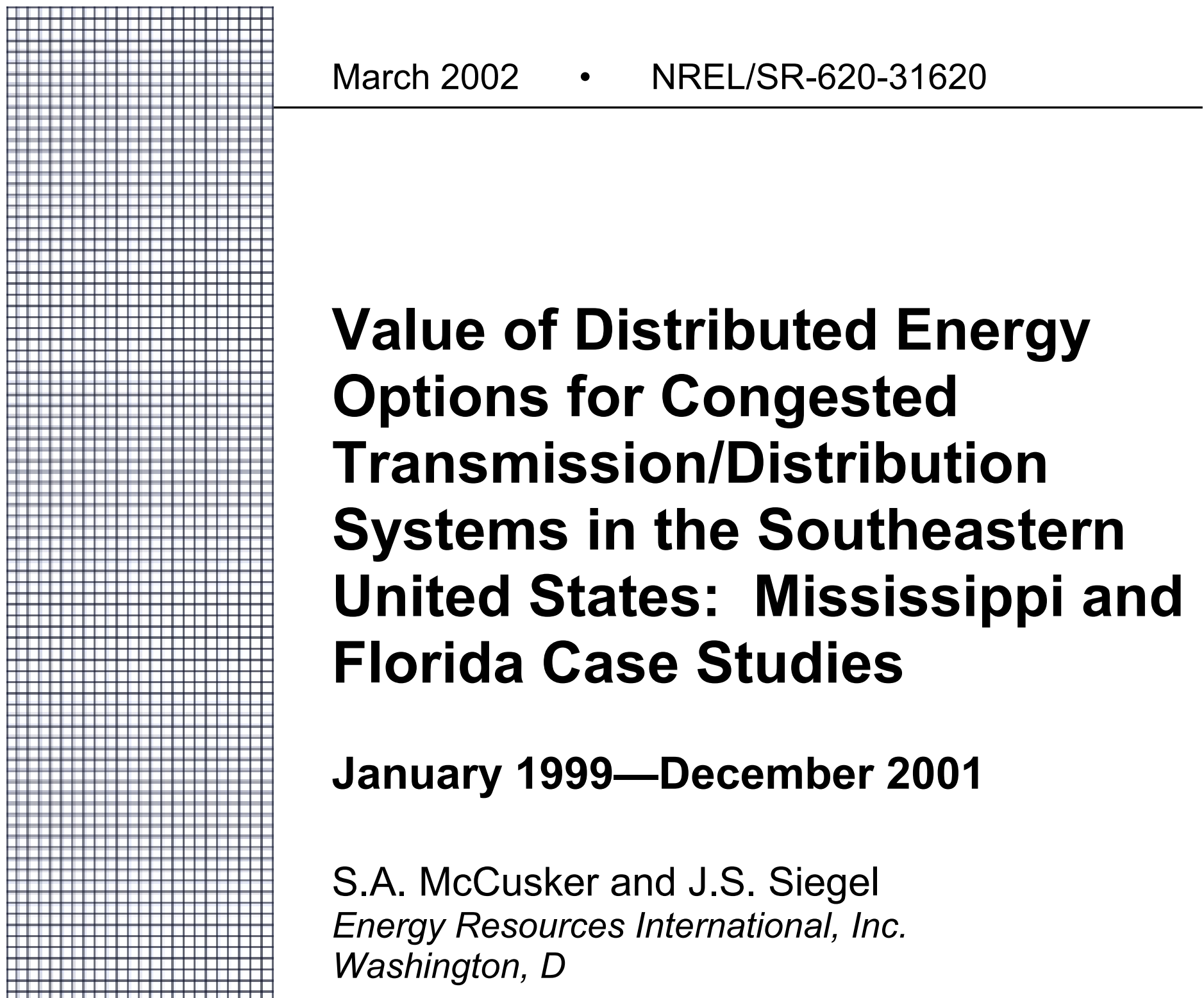

NREL Technical Monitor: Larry Goldstein

Prepared under Subcontract No. KADC-1-31420-01

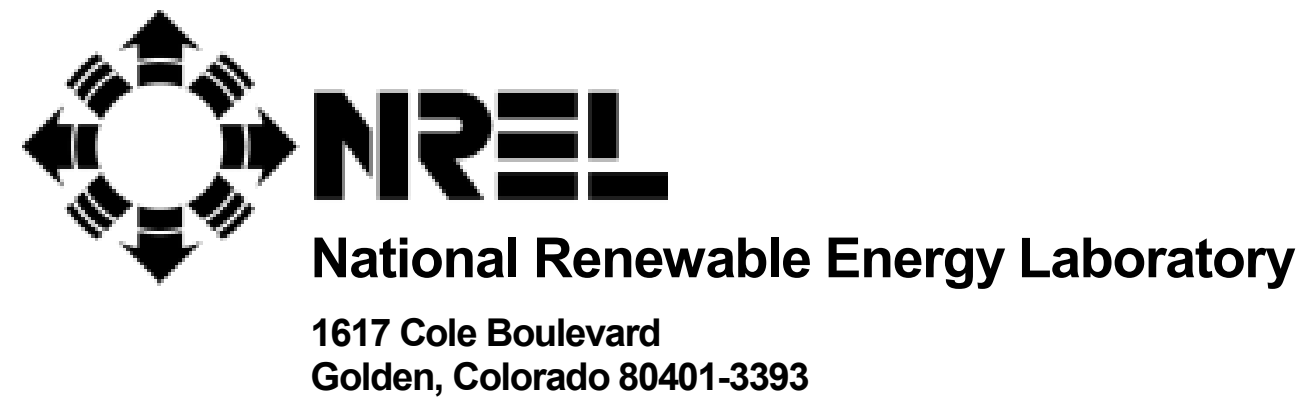

NREL is a U.S. Department of Energy Laboratory

Operated by Midwest Research Institute $\bullet$ Battelle $\bullet$ Bechtel

Contract No. DE-AC36-99-G010337 


\section{NOTICE}

This report was prepared as an account of work sponsored by an agency of the United States government. Neither the United States government nor any agency thereof, nor any of their employees, makes any warranty, express or implied, or assumes any legal liability or responsibility for the accuracy, completeness, or usefulness of any information, apparatus, product, or process disclosed, or represents that its use would not infringe privately owned rights. Reference herein to any specific commercial product, process, or service by trade name, trademark, manufacturer, or otherwise does not necessarily constitute or imply its endorsement, recommendation, or favoring by the United States government or any agency thereof. The views and opinions of authors expressed herein do not necessarily state or reflect those of the United States government or any agency thereof.

Available electronically at http://www.osti.gov/bridge

Available for a processing fee to U.S. Department of Energy

and its contractors, in paper, from:

U.S. Department of Energy

Office of Scientific and Technical Information

P.O. Box 62

Oak Ridge, TN 37831-0062

phone: 865.576.8401

fax: 865.576.5728

email: reports@adonis.osti.gov

Available for sale to the public, in paper, from:

U.S. Department of Commerce

National Technical Information Service

5285 Port Royal Road

Springfield, VA 22161

phone: 800.553.6847

fax: 703.605.6900

email: orders@ntis.fedworld.gov

online ordering: http://www.ntis.gov/ordering.htm

Printed on paper containing at least $50 \%$ wastepaper, including $20 \%$ postconsumer waste 


\section{ACKNOWLEDGMENTS}

The authors wish to thank the National Renewable Energy Laboratory (NREL) and the U.S. Department of Energy's Office of Power Technologies for their funding support. The authors also wish to thank reviewers at NREL for comments and suggestions on earlier versions of this report. 


\section{TABLE OF CONTENTS}

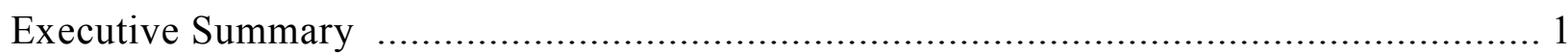

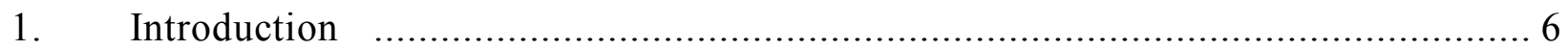

2. Modeling Framework and DG Mitigation Options ........................................... 9

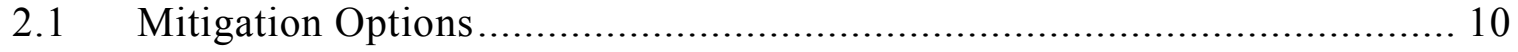

3. Mississippi Site Constraints, Mitigation Options and DG Costs and Benefits ............. 12

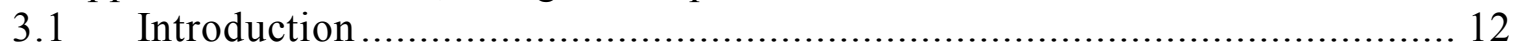

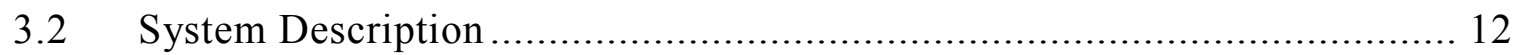

3.3 Transmission and Distribution Constraints ......................................... 12

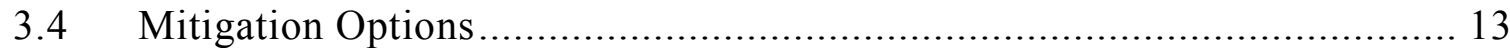

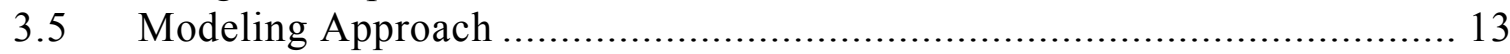

3.6 Benefit/Cost Analysis for the Mississippi Site …...................................... 14

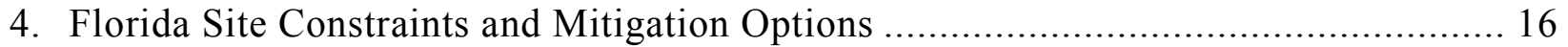

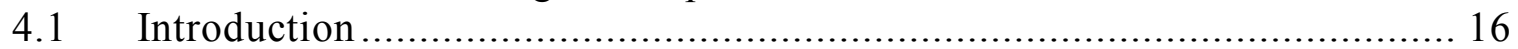

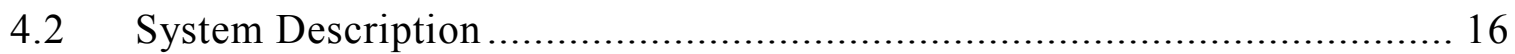

4.3 Transmission and Distribution Constraints .......................................... 17

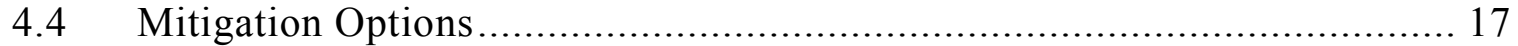

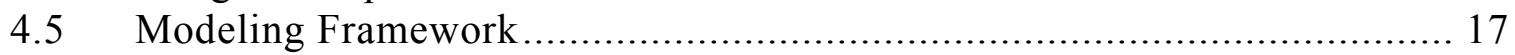

4.6 Benefit/Cost Analysis for the Florida Site ……..................................... 18

5. Implications and Potential for Other Site Applications......................................... 20

Appendix A: Model Summary ……….................................................................... A-1

Appendix B: Federal and State Financial Incentives Available to DG Projects................. B-1

Appendix C: Assumptions and Model Configuration: Mississippi .................................

Appendix D: Assumptions and Model Configuration: Florida.................................. D-1

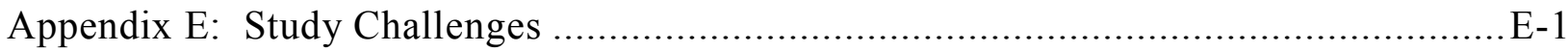




\section{LIST OF TABLES}

Table 1 Summary of Change in Costs for the Mississippi System of DG Option

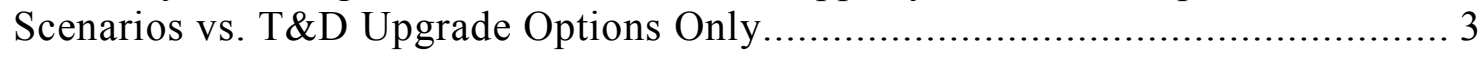

Table 2 Summary of Change in Costs for Installing DG at the Florida Site ................... 4

Table 3 Qualitative Effects of Various Issues on DG Value.................................... 4

Table 4 DG Mitigation Options ................................................................. 11

\section{LIST OF FIGURES}

Figure 1 Overall Net Present Value Costs for Scenarios (a) and (b) ........................ 14

Figure 2 Net Present Value DG Net Costs and Benefits......................................... 15

Figure 3 Break-even Transmission Upgrade Costs ........................................ 18

Figure 4 Coordination of the Three Types of Models ...................................... A-1 


\section{EXECUTIVE SUMMARY}

This report explores the ability of distributed generation (DG) options to provide costeffective alternatives to central station generation, transmission, and distribution upgrades for alleviating transmission and distribution congestion. The need for this study was driven by three major factors:

1. DOE's DG program, while quite successful in showing the value of DG in large portions of the United States, has been less successful in the Southeast, likely because of the low energy prices, high excess electrical capacity, and lack of electricity deregulation in the region.

2. Lack of DG-related analysis that uses real world data on specific sites that can be used as good indicators of the issues and benefits of DG.

3. Interest on behalf of DOE in analysis in two southern states that can be used to show the value of DG to several key Congressional officials from the states.

To demonstrate this ability for constrained sites in systems in the states of Florida and Mississippi, the Electricity Asset Evaluation Model (EAEM) is used to assess the costs and benefits of installing DG options to reduce load in areas with transmission congestion versus upgrading the transmission and distribution (T\&D) systems. ${ }^{1}$ The Florida case is a cooperative-wide study in which the participating generation and transmission (G\&T) and distribution cooperatives have identified an area currently experiencing power flows near transmission line limits. Given projected load increases for the area over the $2002-2006$ period, some action is required to prevent electricity supply shortages in the area as the projected loads increase beyond the transmission line limits. The Mississippi case considers a part of the system in which supply from central station generating units in the study area would be limited by transmission congestion.

For both sites, the EAEM is used to evaluate the system effects over the study's 2002 2006 timeframe of considering DG options. Given estimated load requirements for $2002-$ 2006, the model determines the best mix of central generation, DG, transmission, and distribution additions to minimize the costs of meeting those load requirements. The costs include both the capital costs of the investments and expected production costs based on generating unit dispatch and power flows. Appendix A discusses the EAEM in greater detail.

To determine the potential costs and benefits of the DG options for alleviating transmission congestion in each case, the model is run with scenarios that include DG alternatives as power supply options as well as a scenario that does not include DG alternatives. Costs for the DG scenarios include the capital and production costs of the DG units and any increases in unserved energy costs that result from installing and operating the DG options.

\footnotetext{
${ }^{1}$ The systems analyzed in this study are typical systems based on information from utilities and cooperative systems in Mississippi and Florida. The study is an illustrative first step based on available information and simplified system representations that do not include, for example, reactive power flows and outage contingencies; they would be included in an analysis in the next step.
} 
Benefits of DG are the avoided costs (or cost savings) of the DG scenarios - as compared to the no DG scenario - of reduced central production and capital costs, and any decreases in unserved energy costs that result from installing and operating the DG options.

The analysis results show that, while the distribution line between the central system and the local site in the Mississippi case has adequate capacity, it is connected to a constrained central system loop. The value of DG in Mississippi is based on its ability to alter power flows - consequently reducing congestion in the loop and allowing more production from less expensive units - and to offset expensive central system peak generation. The DG capacity added to the Mississippi system (5.2 MW) is less than the peak loads of the area in which it is installed, and it is installed as a single unit.

For the Mississippi case, the most cost-effective option was one in which DG was added in combination with a subset of potential central station generation and transmission upgrades. ${ }^{2}$. Table 1 summarizes net present value cost variations between the scenarios over the $2002-2006$ study period for the Mississippi system. The numbers indicate the change in costs resulting from the use of DG in combination with T\&D and central station upgrades versus T\&D and central station upgrades alone, with numbers in parentheses representing cost reductions. ${ }^{3}$ As can be seen, there is a cost savings of $\$ 1.25$ million - at a benefit to cost ration of 1.5 - when DG, T\&D, and central station upgrades are considered together compared to $T \& D$ and central station upgrades alone. . It should be noted that, for the purposes of this study and with the resource and time constraints that were imposed, some simplifying assumptions were made that are discussed later in this report. It is expected that the results would be even more favorable for DG, if these issues were analyzed in detail.

\footnotetext{
${ }^{2}$ These scenarios, which represent one set of possible outcomes given the assumptions in Appendix C, suggest that DG options could be cost-effective alternatives. Changes in these assumptions could lead to variations in the cost-effectiveness of DG. Sensitivity analysis of these assumptions is proposed for a follow-on study.

${ }^{3}$ Total capital and production costs for the T\&D Upgrade Options scenario were approximately \$423 million, and included central production, generation capital, and T\&D upgrade costs. Therefore, the costs and benefits of the two scenarios are relatively small in comparison.
} 


Table 1. Summary of Change in Costs for the Mississippi System of
T\&D/DG Options Scenario vs. T\&D Upgrade Options Only ${ }^{4}$
\begin{tabular}{|l|c|}
\hline Central Prod. Costs & T\&D/DG Options \\
\hline T\&D Upgrade Costs & $(\$ 1,470,000)$ \\
\hline TOTAL $\Delta$ BENEFITS & $(\$ 3,270,000)$ \\
\hline DG Cap. Costs & $\$ 1,040,000)$ \\
\hline DG Prod. Costs & $\$ 1,220,000$ \\
\hline $\begin{array}{l}\text { Unserved Energy } \\
\text { Costs }\end{array}$ & $\$ 230,000$ \\
\hline TOTAL $\Delta$ COSTS & $\$ 2,490,000$ \\
\hline $\begin{array}{l}\text { SAVINGS FOR USING } \\
\text { DG }\end{array}$ & $\mathbf{( \$ 1 , 2 5 0 , 0 0 0 )}$ \\
\hline $\begin{array}{l}\text { BENEFIT/COST } \\
\text { RATIO }\end{array}$ & $\mathbf{1 . 5}$ \\
\hline
\end{tabular}

For the Florida system, the transmission constraint occurs on a distribution line between the distribution and G\&T cooperatives that is overloaded during peak load periods. The analysis results show that the value of DG in Florida is based strictly on its ability to meet projected peak loads and avoid unserved energy. The DG units added to the Florida system range from 0.1 to $2 \mathrm{MW}$, and totaled 5.1 MW. These units are added incrementally over three years to add just enough capacity to meet the peak load in each of those three years.

Since transmission upgrade information was not yet gathered by the Florida co-ops, and therefore was not available for comparison purposes, the analysis focused on expected costs of DG alternatives to determine a break-even cost for a transmission upgrade. Table 2 summarizes the net present value change in costs resulting from the addition of DG over the $2002-2006$ study period for the Florida system. The net cost of $\$ 823,000$ represents the breakeven cost of installing T\&D upgrades at the site. In other words, if the cost of T\&D upgrades to relieve constraints at the site is more than $\$ 823,000$ (net present value over the 2002-2006 period), installing DG alone or in combination with other T\&D system upgrades would be more cost effective.

\footnotetext{
${ }^{4}$ The "T\&D Upgrades Options" scenario includes central generation capacity and T\&D upgrade options; the "T\&D/DG Options" scenario includes central generation capacity, T\&D upgrade and DG options. For each category (e.g., Central Prod. Costs) in the table, the values represent the cost for that category under the $\mathrm{T} \& \mathrm{D}$ Upgrade Options scenario minus the cost for that category under the T\&D/DG Options scenario.
} 
Table 2. Summary of Change in Costs for Installing DG at the Florida Site ${ }^{5}$

\begin{tabular}{|r|c|}
\hline & DG Options \\
\hline Central Prod. Costs & $(\$ 1,317,000)$ \\
\hline DG Cap. Costs & $\$ 1,100,000$ \\
\hline DG Prod. Costs & $\$ 1,040,000$ \\
\hline TOTAL & $\$ 823,000$ \\
\hline
\end{tabular}

The results of this study suggest that DGs could have a role in relieving congestion in the two T\&D systems analyzed, and that they should be considered simultaneously with central station generation, transmission and distribution upgrade alternatives when addressing future T\&D congestion concerns. The study, however, is just a first step in understanding the role of DGs in the overall scheme of transmission congestion and energy supply. The limited scope of the study does not quantify several issues or sensitivities that may be important in determining the value of DG. ${ }^{6}$ As Table 3 shows, consideration of most of these issues will act to further increase the value of DG. All of the issues summarized in the Table that show positive effects on the value of DG should be cumulative. However, not all assumptions used in this study reduce the value of DG. Back-up, interconnection and other charges that may be incurred at the two sites studied would add costs to, and therefore lessen the value of DG. ${ }^{7}$ However, the results provide adequate evidence that the benefits of adding DG will reduce costs and that DG should therefore be considered in more detailed, site-specific engineering and costing that normally would follow a planning/screening study such as this.

Table 3. Qualitative Effects of Various Issues on DG Value ${ }^{8}$

\begin{tabular}{|l|c|}
\hline \multicolumn{1}{|c|}{ Issue/Sensitivity } & Effect on DG Value \\
\hline Renewable portfolio standards, tax credits & + \\
\hline Environmental improvements & + \\
\hline Energy security & + \\
\hline Back-up, interconnection and other fees & + \\
\hline Assumptions used in this study & + \\
\hline
\end{tabular}

\footnotetext{
${ }^{5}$ Neither scenario includes central generation capacity options. The "T\&D Upgrades" scenario includes the break-even cost for a T\&D upgrade, and the "DG Options" scenario includes costs for optimal DG alternatives.

${ }^{6}$ Some assumptions that were necessary due to limited data availability may also underestimate the value of DG as summarized in this report. For the Mississippi system, these assumptions include deterministic generator availabilities and simplified load projection estimates. For the Florida system, in addition to deterministic generator availabilities and simplified load projection estimates, details of the transmission system were not available, so the effects of power flow constraints on generator dispatch were not considered.

${ }^{7}$ While quantifying and including in the model all of the qualitative effects in Table 3 would likely alter the magnitude of the costs and benefits calculated in this study, the relative value of DG compared to T\&D upgrades determined in this study would be expected to remain positive.

${ }^{8} \mathrm{~A}$ " +" sign in the "Effect on DG" column indicates non-negative benefits; similarly, a "_" sign indicates non-positive benefits.

${ }_{9}^{9}$ Modeling the central system as a single area (Section 4.6); including only peak and baseload periods in load profile (Section 4.6); modeling generating unit availability as expected capacities (footnote 17).
} 
Some DG technologies, in particular new renewables and fuel cells, receive tax and other financial and regulatory incentives at the federal, and in some cases, state and local levels. These incentives effectively reduce the costs of using the technologies. Since these factors are not considered in the analysis, the value of these options is underestimated. The incentives that are currently available are summarized in Appendix B.

Many of the DG technologies analyzed are advantageous from an environmental perspective when compared against the central station options they would displace. For example, the renewable energy technologies emit no air pollution. The avoidance of air and other pollution has economic value that is not considered in this analysis. This factor also underestimates the value of DG.

Energy security benefits arise from reduced reliance on the transmission and distribution system, and the dispersed nature of DG. Generating small amounts of electricity at many sites reduces the vulnerability to large electricity disruptions that could be caused by terrorist activities or equipment outages. In addition, many of the DG technologies are not dependent upon the availability of fossil fuels that would have to be delivered to the site.

Other potential DG benefits not included in this report that would increase the value of DG include power quality improvement, peak demand support, energy management, and grid/VAR support. However, some important costs of using DG are not included in the calculations summarized in this report. Interconnection fees, electric power back-up charges, and other fees levied by utilities on DG systems would reduce the value of DG.

The remainder of this report is organized as follows. In Section 1, background information is provided on selection of the sites and on the sites themselves. In Section 2 the modeling framework and DG mitigation options are presented. Sections 3 and 4 describe the constraints and central capacity mitigation options and the benefits and costs of DG options for the Mississippi and Florida sites, respectively. Section 5 discusses implications and potential of the EAEM for other applications. 


\section{INTRODUCTION}

Introduction of competition in wholesale power supply has placed constraints on transmission and distribution (T\&D) systems that did not exist in the past. The electricity price and supply problems that have been prevalent in California and other states are expected to spread further in the future. Even those states not undergoing deregulation or a complete transition to competitive power markets are vulnerable to price increases and supply constraints as site specific issues may exist. Some of the more important issues include:

- Public resistance to new construction of power plants/transmission lines ("not-inmy-back yard" - NIMBY),

- Environmental restrictions limiting (or precluding) new emission sources,

- Transmission bottlenecks,

- Inadequate distribution systems due to age/configuration relative to location (or rate) of economic activity, and

- Terrorist activities or other unforeseen equipment outages.

Distributed energy resources (DERs) are one means of addressing localized electricity supply problems. DER options include, among others:

- Renewable resources - biopower, photovoltaic systems, wind turbines, geothermal;

- Natural gas turbines, fuel cells and reciprocating engines;

- Natural gas-renewable hybrids;

- Demand-side measures; and

- Storage technologies.

Although there is general recognition that DERs can play a potential role in meeting future power supply needs - e.g., power quality improvement, peak demand support, energy management, grid/VAR support, environmental compliance - many stakeholders are not convinced of the benefit of pursuing this strategic supply option or of its technological/economic readiness. In addition, DERs, if improperly located, sized or operated, can create $T \& D$ problems.

As a result, the Department of Energy has launched a DER Initiative. The strategy is intended to mobilize a program of research, development \& demonstration (RD\&D) coupled with systems analyses, integration, and institutional, regulatory and outreach initiatives in collaboration with industry, federal, state and local regulators, and other stakeholders. An early step is to understand the benefits/costs and applicability of DER to resolve T\&D congestion, and the transferability of the DER option to different geographic sites and operational conditions. 
The objective of this analysis is to illustrate, through case study, the benefits and costs of DG (a subset of DER that includes only supply side systems) options to alleviate congestion in typical Florida and Mississippi systems. ${ }^{10}$ The analysis uses the Electricity Asset Evaluation Model (EAEM) to choose generating and transmission and distribution (T\&D) asset additions that minimize expected total system capital and production costs for the years $2002-2006$. The benefits and costs of DG options are determined by comparing the results of model runs that include DG options to results of model runs that allow only T\&D and central generating asset additions. ${ }^{11}$ This is but one part of the analysis that must be completed to ultimately determine whether DG systems could or should be sited at a particular location. For example, analysis of each of the site-specific issues identified above may need to be analyzed. ${ }^{12}$ However, this screening analysis gives confidence that DG should be considered along side of, and in combination with other options to minimize costs of ensuring reliable electricity supply in the regions analyzed.

The States of Florida and Mississippi were selected as the regions of focus for this case study because: (1) they are dominated by large, regulated utilities that may not have the incentive, culture, experience, resources or tools to fully consider DG options, (2) electric utility deregulation is progressing very slowly, and as a result, may not be available to fully open competition for DG projects, and (3) DG is advancing slowly as compared with some other regions of the country. As a result, if the analysis shows that DG offers potential advantages over other options normally considered by utilities in these states, it may influence the utilities in these states to give DG more consideration in the future.

For the Florida system, the cooperative identified a site where power flows are near line capacity limits, and loads are expected to increase in the near future. While the cooperative has begun to examine this problem, it has not proposed any concrete solutions. Thus, this study identifies the most cost-effective DG options and determines a break-even cost for a transmission upgrade based on the DG costs. For the Mississippi system, the EAEM was used to identify the site with the highest expected marginal costs ( $\$ / \mathrm{MW})$ over the planning horizon and to compare the DG options to transmission upgrade options to determine if DGs would be a viable and economic alternative. ${ }^{13}$

\footnotetext{
${ }^{10}$ The systems are based on information provided by utilities and cooperatives in Florida and Mississippi.

${ }^{11}$ The central system is assumed to include all generating units, T\&D lines, and load buses with the exception of the congested site. Central generating asset additions are distinguished from DG options by their size (several hundred MWs, in this case, vs. ten or fewer for DG) and location. For this study, DG options are considered only for the selected site.

${ }^{12}$ The EAEM is an expansion planning model designed as an initial screening tool to identify constrained sites within a larger geographic area and determine if DG has positive value at these sites. With additional resources, this study could be expanded to include quantitatively the qualitative issues presented in Table 3 . More detailed studies focused on the smaller geographic area of the identified sites (e.g., reactive power studies) would be appropriate prior to DG installation.

${ }^{13}$ Since the marginal costs represent the potential savings of reducing the site's load, the site with the highest expected marginal costs is selected as the site that would benefit most from a load reduction.
} 
The remainder of this report presents the modeling framework and DG mitigation options for the studies (Section 2), describes the constraints, central mitigation options and DG costs and benefits at each site (Section 3 and 4), and discusses implications and potential for other applications (Section 5). The appendices present study challenges, modeling assumptions, and summaries of the model and the analysis methodologies. 


\section{MODELING FRAMEWORK AND DG MITIGATION OPTIONS}

The objective of the model is to determine asset additions that will minimize total system capital and production costs over the five-year study time period. ${ }^{14}$ In some cases, costs will be minimized by adding generating or T\&D capacity. For example, if energy from the marginal peaking unit is very costly or $T \& D$ constraints limit power flows from less expensive units, it may be more cost effective to add new, cheaper capacity. The decision of whether or not to add new capacity involves two questions:

- Where should new assets be installed to minimize overall costs?

- When should new assets be installed to minimize overall costs?

Due to the interconnectedness of the system over space and time, to actually minimize overall costs these two questions need to be answered simultaneously. An asset added to alleviate a constraint in one area of the system may alter power flows in such a way as to affect generation of another unit in a different area of the system. The same is true over time. An asset added to alleviate a constraint in one time period may affect generation of a different unit in another time period. This example extends further across areas and time periods. An asset added to alleviate a constraint in one area in one time period may affect generation in another area in another time period.

The comprehensive modeling framework of the EAEM provides a means to predict and track the changes in production and power flows caused by asset additions. Since it simultaneously determines generating unit dispatch and power flows over the whole system for the entire planning period, the EAEM inherently recognizes the effects of asset additions across time and space, and considers them in its optimization. ${ }^{15}$ The "effects of asset additions across time and space" are reflected in each area's marginal cost in each time period.

The marginal cost $(\$ / \mathrm{MW})$ for each bus during each load period represents the cost of meeting additional load at that bus during that load period. If there are no transmission constraints, then the resulting generation pattern is least-cost dispatch. With least-cost dispatch, the lowest cost unit will generate to its capacity, then the next cheapest unit and so on, until the load at every bus has been met. The plant that meets the last MW of demand (i.e., the unit currently operating with the highest production cost) is the marginal plant. In the absence of transmission constraints, this is the plant that would generate an

\footnotetext{
${ }^{14}$ The investments are amortized over 20 to 30 year time periods, but only the costs that occur in the fiveyear study period are considered.

${ }^{15}$ Other methods are valuable for targeting opportunities in existing systems, but unlike the EAEM, were not designed to optimize operation of the entire system for long-term expansion planning (see e.g., Shugar, D.S., "Benefits of Distributed Generation in PG\&E's Transmission and Distribution System: A Case Study of Photovoltaics Serving Kerman Substation," PG\&E R\&D, Report 007.5-92.9, November 1992; and Howard Wenger, Tom Hoff and Dale Furseth, Pacific energy Group; Christy Herig, National Renewable Energy laboratory; and John Stevens, Sandia National Laboratory, "QuickScreen Software for Distributed PV Evaluation," http://www.pacificenergy.com/quickscn.htm).
} 
extra MW demanded at any bus. Thus, the marginal cost at all buses equals the production cost of the marginal plant. ${ }^{16}$

In the presence of transmission congestion, however, the constraints may prevent power generated at the cheapest available plant (i.e., not already operating at capacity) from reaching the bus with the additional MW demand. Thus, the cost of meeting an extra MW of demand can vary by bus. Therefore, differences in bus marginal costs indicate the presence of transmission constraints - and identify sites for potential DG applications.

Once the potential sites for DG applications have been identified, the model evaluates the cost-effectiveness of the DG options versus traditional T\&D and central station upgrades. In conducting this evaluation, the model again determines generating unit dispatch and power flows over the whole system for the entire planning period; in this case, however, it includes DGs when determining which assets minimize overall system capital and production costs. ${ }^{17}$

\subsection{MITIGATION OPTIONS}

Central station generation, DG, and T\&D enhancements are all options for relieving T\&D congestion. Strategically located central generating units can alleviate congestion by reducing generation by units on congested parts of the system. DGs can be sited to reduce loads on constrained segments of the T\&D system. Upgrades to the T\&D system can increase permissible power flows in congested areas. Congestion, however, typically occurs during a small number of hours per year; thus upgraded T\&D capacity is not usually needed during the bulk of the year. Generating units, on the other hand, while installed primarily to relieve peak load congestion, can be used throughout the rest of the year to offset generation from more expensive units.

Table 4 contains the DG mitigation options considered for this study. These options include microturbines, fuel cells, combustion turbines, photovoltaics and generic peak and baseload DG units from EIA NEMS. ${ }^{18}$ Sections 3 and 4 discuss central system mitigation options for each site.

\footnotetext{
${ }^{16}$ This is not strictly true if new units can be built, because if a new unit is the marginal plant, then the marginal cost includes a capacity component as well as energy.

${ }^{17}$ The model identifies a general area for DG installation, not a specific location on the distribution line, which would be determined in a detailed site analysis.

18 Generic DG peaking units are basically an average of microturbines, gas-fired combustion turbines, and three types of reciprocating engines; generic DG baseload units are assumed to be a mix of heavy-duty microturbines, combustion turbines, engines, and fuel cells ("Model Documentation Electricity Capacity Planning Submodule of the Electricity Market Module," Prepared by: Nuclear and Electricity Analysis Branch, Energy Supply and Conversion Division, Office of Integrated Analysis and Forecasting, Energy Information Administration, March 1994).
} 
Table 4. DG Mitigation Options

\begin{tabular}{|c|c|c|c|c|c|}
\hline Unit & $\begin{array}{l}\text { Output } \\
\text { (kW) }\end{array}$ & $\begin{array}{l}\text { Total Heat } \\
\text { Rate HHV } \\
\text { (Btu/kWh) }\end{array}$ & $\begin{array}{c}\text { Installed } \\
\text { Costs }(\$ / k W)\end{array}$ & $\begin{array}{c}\text { Fixed O\&M } \\
\text { (\$/kW-yr) }\end{array}$ & $\begin{array}{c}\text { Variable O\&M } \\
(\$ / \mathrm{kWh})^{19}\end{array}$ \\
\hline $\begin{array}{l}3 \mathrm{X} \text { Parallon } \\
75 \mathrm{Kw} \\
\text { microturbines }\end{array}$ & 225 & 13,326 & 1000 & 75 & 0.004 \\
\hline $\begin{array}{l}\text { Solar Taurus } \\
60 \text { combustion } \\
\text { turbine }\end{array}$ & 5,200 & 12,442 & 575 & 8.3 & 0.0045 \\
\hline $\begin{array}{l}\text { NEMS Utility } \\
\text { DG Peak }\end{array}$ & 1,000 & 10,620 & 546 & 12.26 & 0.0225 \\
\hline $\begin{array}{l}\text { NEMS Utility } \\
\text { DG Base }\end{array}$ & 2,000 & 10,991 & 608 & 3.92 & 0.01475 \\
\hline $\begin{array}{l}\text { Buildings } \\
\text { Distrib. Fuel } \\
\text { Cell }\end{array}$ & $\begin{array}{c}5 \text { for res.; } \\
200 \text { for comm. }\end{array}$ & 9,478 & 3674 & 87 & 0 \\
\hline $\begin{array}{l}\text { Buildings } \\
\text { Distrib. PV }\end{array}$ & $\begin{array}{c}2 \text { for res.; } \\
10 \text { for comm. }\end{array}$ & n.a. & 7870 & 10 & 0 \\
\hline $\begin{array}{l}\text { Comm. Bldg } \\
\text { Microturbine } \\
\mathrm{CHP}^{20}\end{array}$ & 100 & 13,277 & 1970 & 90 & 0 \\
\hline $\begin{array}{l}\text { Industrial CHP } \\
\text { Gas Turbine } \\
\text { CHP }\end{array}$ & 5,000 & 12,375 & 1075 & 0 & 0 \\
\hline
\end{tabular}

Sources: Data used by EIA in the NEMS model (in one case modified by DOE/EERE/OPT), and/or provided by the Office of Energy Efficiency and Renewable Energy.

\footnotetext{
${ }^{19}$ Variable O\&M costs do not include fuel costs.

${ }^{20}$ The possible benefits of waste heat from the combined heat and power (CHP) systems are not quantified or credited in the model.
} 


\section{MISSISSIPPI SITE CONSTRAINTS, MITIGATION OPTIONS AND DG COSTS AND BENEFITS}

\subsection{INTRODUCTION}

For the Mississippi system, the EAEM is used to identify the most constrained site over the planning horizon, and to compare the DG options in Table 4 to transmission upgrade alternatives to determine if DGs might be a viable and economic alternative. This section describes the Mississippi system and its transmission constraint, and discusses mitigation options.

\subsection{SYSTEM DESCRIPTION}

The Mississippi system operates several plants throughout the transmission system, with units ranging in capacity from 16 to $200 \mathrm{MW}$ and using a mix of fuels including coal, natural gas, and oil. Appendix $\mathrm{C}$ contains transmission line capacity and generating unit operating information.

System peak loads are projected to increase by approximately one percent per year through 2006, and annual system energy growth rates are projected to be greater than four percent over the same period. Peak and annual energy growth projections by bus were not available. Appendix $\mathrm{C}$ presents the assumptions and methodology for estimating bus loads from the available data.

Generation capacity additions assumed for the study over the 2002 - 2006 time period include $200 \mathrm{MW}$ from natural gas-fired units; transmission upgrade alternatives assumed include new lines, rebuilt lines, and uprated lines.

\subsection{TRANSMISSION AND DISTRIBUTION CONSTRAINTS}

As Section 2 discusses, potential T\&D constraints are found by identifying the bus with the highest expected marginal costs. This is done in the first part of the modeling process, in which the EAEM is run as a production-costing model. As a production-costing model, the existing units are dispatched-subject to transmission constraints - to meet forecasted load for the study timeframe, without the addition of new infrastructure. If transmission congestion exists, bus marginal costs will vary throughout the system. The bus with the highest marginal cost for the study period is the most constrained site.

Using the highest marginal cost criterion, the EAEM identified a constrained site in the Mississippi system. The projected 2002 loads fed from this site range from an offpeak load of $2 \mathrm{MW}$ to a peak load of $6 \mathrm{MW}$. These are not the highest loads in the system, yet the high marginal costs at this site indicate that reducing them can produce the greatest cost benefit to the system. 
The T\&D constraints that cause marginal cost variations are not only thermal line limits (i.e., upper bounds on MWs) but also parallel path or loop flow constraints. In the case of loop flow, power flows on all lines connected in a loop affect the power that can flow on all other lines in the loop. This is the nature of the constraint at the selected site. The local line from the loop to the load site has adequate capacity, but constraints on flow around the loop restrict power flow from the loop to the local line. In this analysis (given generating unit availability and load assumptions), these constraints result in unserved load at this site during all of the study load periods. ${ }^{21}$

\subsection{MITIGATION OPTIONS}

In addition to assumed generating unit installations between 2002 and 2006, several transmission upgrade alternatives are evaluated. These upgrade alternatives include adding new lines, rebuilding lines, and uprating lines; they range in cost from $\$ 50,000$ to nearly $\$ 4$ million.

\subsection{MODELING APPROACH}

To assess the benefits and costs of DG systems to help address the Mississippi site transmission constraints, the following steps were taken in this study:

1) Congestion points were identified by running the EAEM with the existing T\&D system, existing central station generation capacity and assumed capacity installations, and projected loads. Results indicated that increasing generation capacity with the existing $T \& D$ system would lead to $T \& D$ congestion and spatially-varying marginal costs. The highest marginal cost site became the site for potential DG installation.

2) The EAEM was run for the following scenarios:

a) As in 1), but all assumed T\&D upgrades were included to determine the costs of meeting projected loads with existing and planned central station generation capacity and assumed T\&D upgrades - with no DG options.

b) As in 1), but T\&D upgrade options and DG options were included. This scenario provides the most cost-effective assortment of DG/T\&D options. Comparing the costs of this scenario to those of scenario a) indicates the value of considering all resources simultaneously.

${ }^{21}$ Generating unit availabilities were modeled as expected capacities, which has been demonstrated to produce a lower bound on expected costs, thus underestimating DG benefits. Different load assumptions could increase or decrease the value of DG, depending on the locations and load periods of the altered loads. 


\subsection{BENEFIT/COST ANALYSIS FOR THE MISSISSIPPI SITE}

Figure 1 shows the overall expected capital and production costs of meeting the projected Mississippi system load for the scenarios described in (a) and (b) above. Column one represents costs for scenario (a). This scenario, which includes central transmission and generation capacity options but does not include DG options, presents the highest cost solution. ${ }^{22}$

Column two in Figure 1 represents the costs for scenario (b), which includes central generation and transmission capacity and DG options. In this scenario, one 5.2 MW Solar Taurus 60 combustion turbine (CT) DG unit is added in 2003. The Solar Taurus 60 CT is dispatched during the 1228 highest load hours each year from 2003-2006. During all of these hours, its output into the system alters power flows in the constrained loop, thus contributing to transmission congestion relief. The other main benefit of the CT is that it offsets generation from high cost oil-burning units during the peak load hours. The added capacity and energy from the CT are benefits that transmission upgrades do not offer. This scenario results in cost reductions of $\$ 1,250,000$ over scenario a) and is the lowest cost option.

Figure 1. Overall Net Present Value Costs for Scenarios (a) and (b)

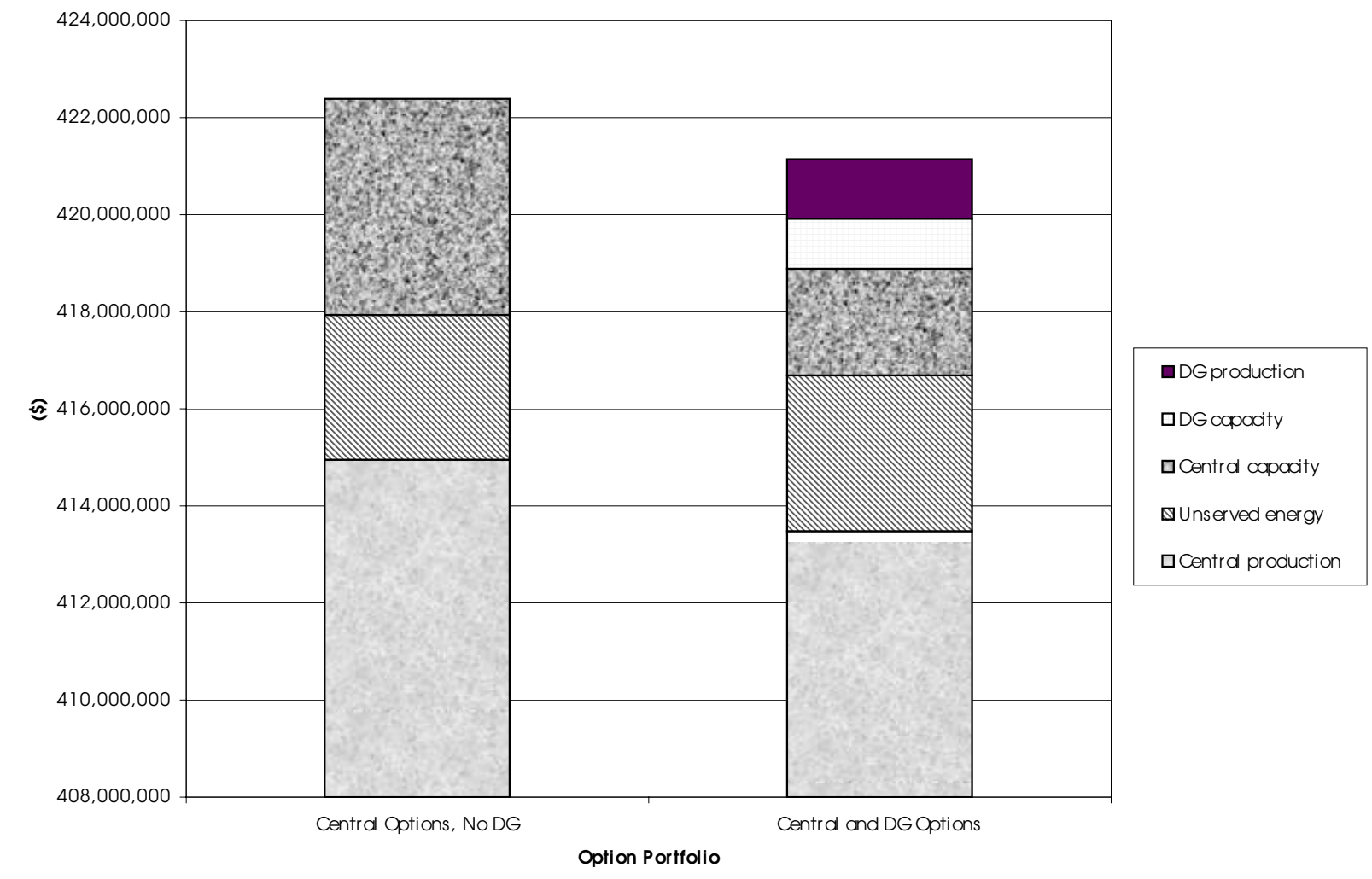

${ }^{22}$ Note that the costs of the scenarios are quite close, with less than one percent different between them. 
Figure 2 demonstrates the net costs and benefits of considering the DG options along with central station options in the Mississippi system. In Figure 2, the benefits are the avoided costs of the DG/central station scenario (c) compared to scenario (a), which includes only central station options. For example, as Figure 2 shows, choosing the DG/central station option reduces central station production costs and central station capacity costs. These cost savings are a benefit of DG. Similarly, choosing the DG/central station option increases some of the costs. The amount of the increases in unserved energy and DG capacity and production costs are the net costs of DG. The net benefits of DG are the benefits of DG minus the net costs of DG. For the Mississippi system, the net benefits are negative, indicating that DG options can provide cost savings and should be considered simultaneously with central generation and transmission capacity assets for meeting projected loads and alleviating transmission congestion. ${ }^{23}$

Figure 2. Net Present Value DG Net Costs and Benefits

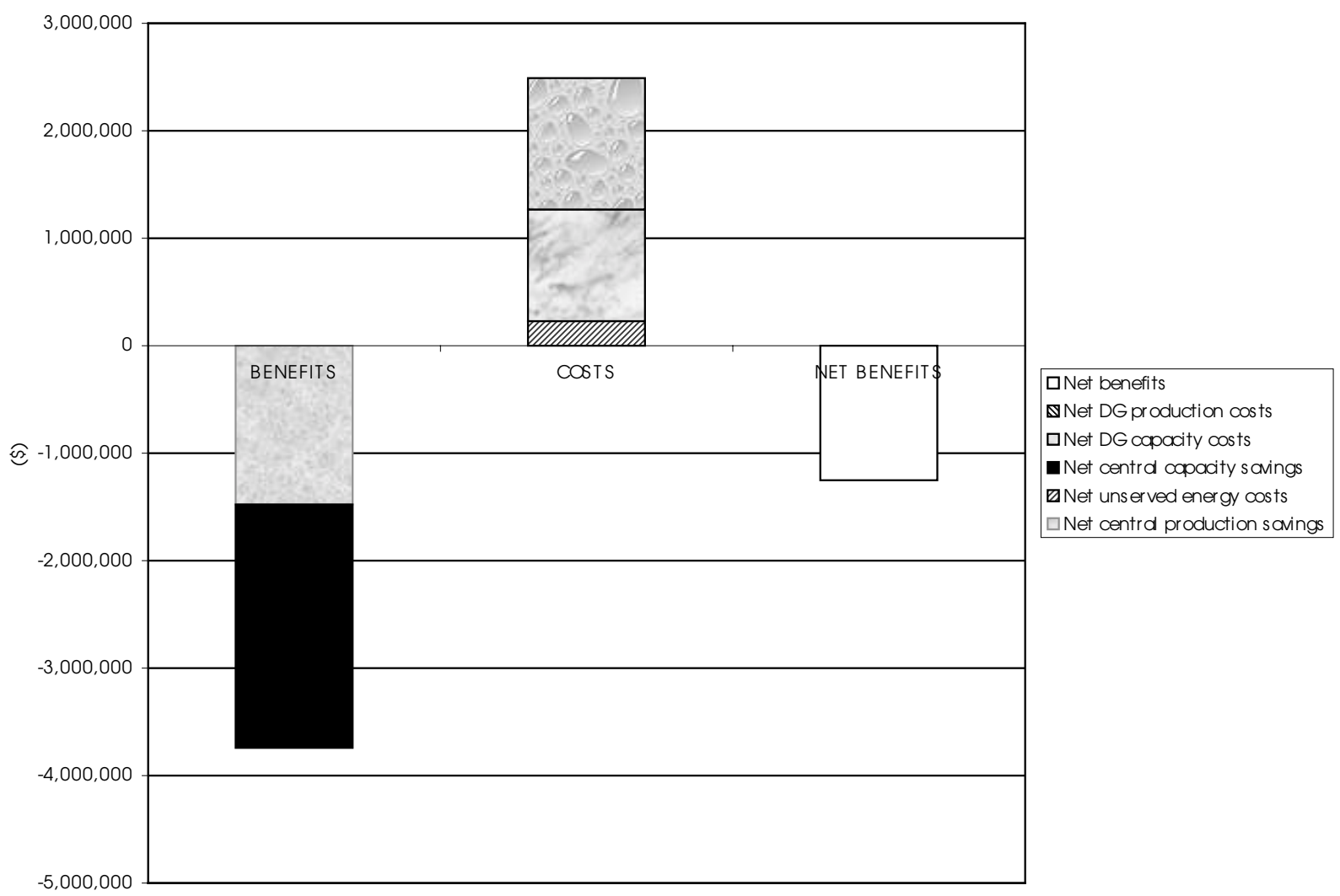

\footnotetext{
${ }^{23}$ The benefit/cost ratio for the DG/central scenario is slightly greater than one. While this ratio does not
} overwhelmingly favor DG options, it does indicate that DGs are viable alternatives worthy of consideration. 


\section{FLORIDA SITE CONSTRAINTS AND MITIGATION OPTIONS}

\subsection{INTRODUCTION}

For the Florida system, the cooperative identified a site where power flows are near line capacity limits, and loads are expected to increase in the near future. While the cooperative has begun to examine this problem, it has not proposed any concrete solutions. Thus, this study identifies the most cost-effective DG options and uses the costs of the DG solution to determine the break-even cost for a transmission upgrade mitigation option. This section describes the Florida system and its transmission constraint, and explains how the cost of a transmission upgrade mitigation option was determined.

\subsection{SYSTEM DESCRIPTION}

The Florida site is an area within a distribution cooperative that serves retail load. The distribution cooperative operates under a long-term contract to receive wholesale electricity from a generation and transmission (G\&T) cooperative. The distribution cooperative has no baseload generation of its own, but does operate several DG peak-shaving units throughout its system.

The G\&T cooperative is a wholesale cooperative that provides full requirements to its distribution system members using a mixture of owned and purchased capacity resources. ${ }^{24}$ It is obligated to serve all load up to specified capacity commitment levels and to provide adequate reserves, relying on partial requirement providers and spot market purchases to serve any load above the capacity commitment levels. ${ }^{25}$ The G\&T cooperative has eight power supply contracts in effect during the 2002-2006 study period.

Distribution system members are served from the G\&T cooperative's own transmission system and from the transmission systems of two other utilities. The G\&T cooperative purchases network transmission service from these two utilities under long-term contracts.

Both the distribution and the G\&T cooperative are winter peaking systems. The distribution cooperative provided 2002, 2004, and 2006 winter and summer peak load projections for the constrained site and the system load factor. Available load data for the G\&T cooperative included year 2000 monthly peak loads, year 2000 total energy consumption, and projected statewide peak load growth through 2006. These load data were used to estimate baseload and peak loads for the years 2002 to 2006. Appendix D presents the assumptions and methodology for estimating the loads.

24 "Review of Electric Utility 2000 Ten-Year Site Plans," Florida Public Service Commission, Division of Safety and Electric Reliability, Division of Economic Regulation, Division of Competitive Services, December, 2000.

${ }^{25}$ Ibid. 


\subsection{TRANSMISSION AND DISTRIBUTION CONSTRAINTS}

The constrained site for this study is served from a $69 \mathrm{kV}$ corridor that is experiencing overload problems, with one section in particular loaded near its limit. Additionally, projected peak loads for this area are greater than the line ratings of its distribution line. The $69 \mathrm{kV}$ corridor crosses the boundary between two utilities, one of which provides transmission services to all of the transmission level delivery points of the distribution system in this study. To address this joint problem, the two utilities and the distribution cooperative have assembled a group to examine possible solutions for the overloaded corridor, but no solutions have been proposed at this point.

\subsection{MITIGATION OPTIONS}

Because transmission system improvements are so site-specific, and no particular upgrades have been proposed, the break-even costs of a generic transmission upgrade are determined instead. The break-even cost of the generic transmission upgrade is the cost at which the cooperative would be indifferent between improving transmission capacity and installing DGs. This cost is the difference between the overall costs of the scenario that includes the most cost-effective DG options and the overall costs of the scenario that includes the transmission upgrade at no cost. If the cost of the transmission upgrade is greater than the cost difference, the DG options are the better value, whereas the transmission upgrade is the better value if its costs are less than the cost difference between the two scenarios.

\subsection{MODELING FRAMEWORK}

For the Florida study, the objective of the model is to determine the value of DG alternatives in postponing or eliminating the need for a transmission upgrade between the central system and a local distribution area. With projected loads for the area exceeding the capacity of the distribution line, congestion is foreseen but upgrade alternatives have not yet been proposed. The distribution area loads are currently served exclusively from the central system, with the exception of a few peak-shaving units. With a distribution upgrade, all of the distribution area load could continue to be met with power generation from the central system if it is economical to do so. For this study, central system generation includes generating units the central G\&T cooperative owns and contracts it has to dispatch units belonging to other utilities and independent power producers.

Since actual transmission upgrade cost estimates were not available, the model was run with DG options alone to determine the most cost-effective DG alternatives and the breakeven cost. The model was then run with new transmission capacity added at no cost. The difference between the two model run cost estimates is the break-even cost for the transmission upgrade for the 2002-2006 study period. ${ }^{26}$

\footnotetext{
${ }^{26}$ The transmission upgrade was assumed to be a 30 -year investment, with a stream of annualized costs over a 30-year period. To compare assets with different assumed lives to be added in different years, only the costs that would occur between 2002-2006 were considered in the model. Comparing the two model runs yields the sum of the annualized NPV capacity costs over the five-year period.
} 


\subsection{BENEFIT/COST ANALYSIS FOR THE FLORIDA SITE}

In the no transmission upgrade case, three different DG options are selected: (1) one NEMS Utility DG Peak unit for installation in 2002, (2) two NEMS Utility DG Base units - one in 2003 and another in 2004, and (3) one microturbine CHP unit in 2003. All units are dispatched only during the peak load periods of the year they are installed and all following years.

In the transmission upgrade case, the transmission upgrade is added at no cost, resulting in all of the distribution area's load being served by central generating units; no DG options are selected. The cost of this case is subtracted from the cost of the DG case, with the difference being the break-even cost for the transmission upgrade, as is shown in Figure 3. For the given assumptions, if the NPV transmission upgrade costs for 2002-2006 are greater than $\$ 823,000$ ( $\$ 3.24$ million total upgrade costs), it would be more cost-effective to install the three DG units as in the no transmission upgrade case. A transmission upgrade with a total cost lower than $\$ 3.24$ million would make the transmission upgrade the more cost-effective alternative.

\section{Figure 3. Break-even Transmission Upgrade Costs}

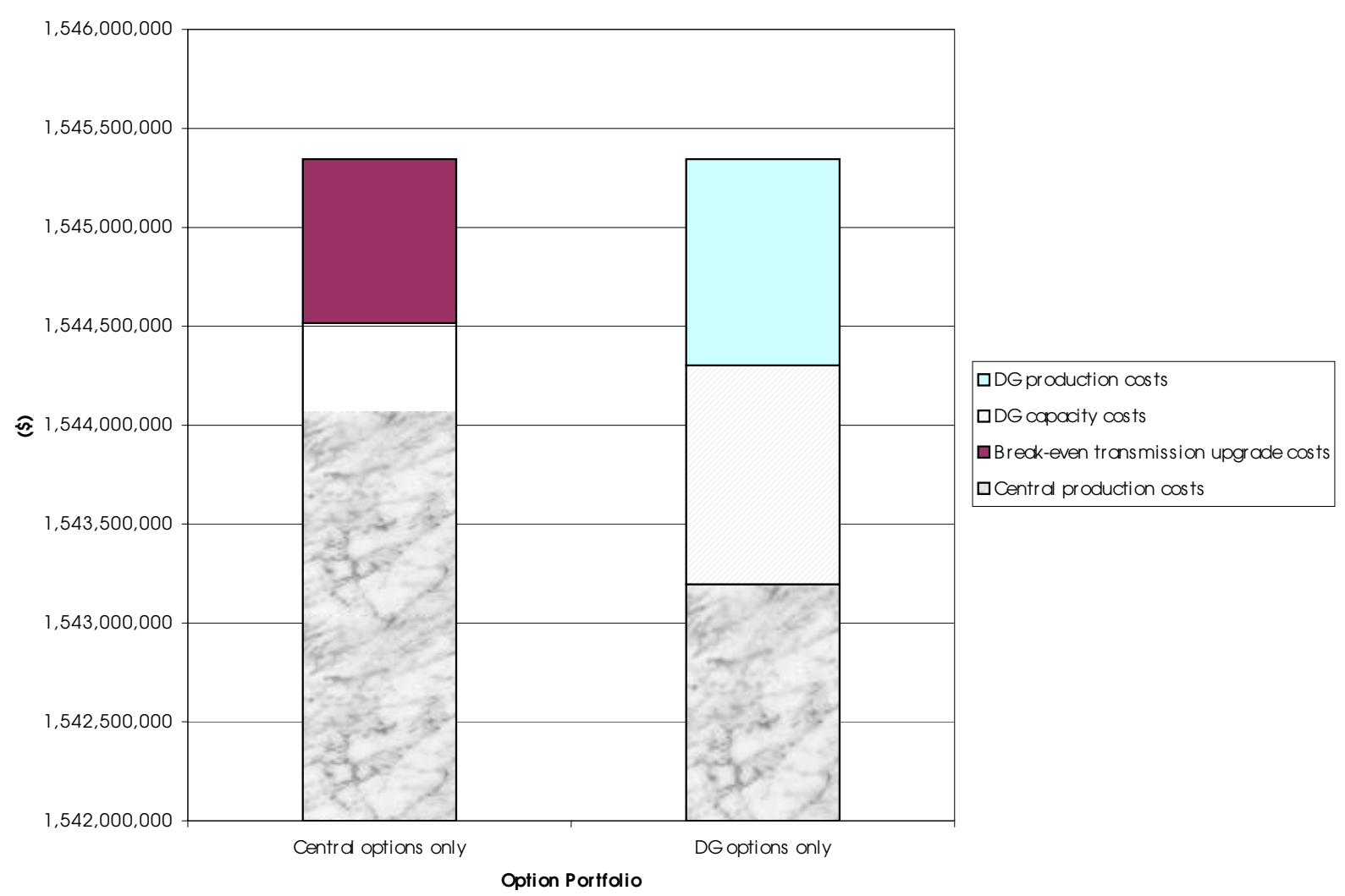

Several assumptions were made to accommodate available data; those that might have affected the break-even cost include: ${ }^{27}$

\footnotetext{
${ }^{27}$ Appendix D discusses these assumptions in greater detail.
} 
- The central (G\&T) system was modeled as a single area. Thus, all transmission constraints other than the one between the G\&T cooperative and the distribution area were not considered. Including the effects of central system transmission constraints could only have increased the costs of supplying power to the distribution area from the central system, making DG options more attractive.

- The load profile included only peak and baseload load periods. Dividing the loads into a greater number of load periods may have resulted in more hours with loads in excess of the distribution line capacity, since some of those loads were averaged into the low load/large number of hours baseload period. Unless the cost of centrally-supplied power for those same load periods decreased, this would have increased the cost-effectiveness of DG options by allowing the fixed DG costs to be shared over more hours. The additional load may also have made possible the addition of a larger, cheaper (per MW) DG unit. 


\section{IMPLICATIONS AND POTENTIAL FOR OTHER SITE APPLICATIONS}

The study results for the Mississippi system suggest that DG options could be competitive with central transmission capacity options if they are evaluated simultaneously. For the Florida system, which has not yet addressed its transmission constraint, results of the study indicate a break-even cost for a transmission upgrade, and the most cost-effective DG options if the transmission upgrade is greater than this cost. For both states, however, the study is just a first step in understanding the role of DGs in the overall scheme of transmission congestion and energy supply. The limited scope of the study does not include several issues that are potentially important in determining the value of DG (e.g., renewable energy tax credits and environmental improvements). Additionally, several assumptions that were necessary due to the lack of availability of some data could have caused DG values to be underestimated, especially in Florida.

For the Florida system, the transmission constraint occurs on a distribution line between the distribution and G\&T cooperatives that is overloaded during peak load periods. The value of DG in Florida is based strictly on its ability to meet projected peak loads and avoid unserved energy. The DG units added to the Florida system range from 0.1 to 2 MW, and totaled 5.1 MW. These units are added incrementally over three years to add just enough capacity to meet the peak load in each of those three years. ${ }^{28}$

In contrast, the distribution line between the central system and the local site in the Mississippi study has adequate capacity, but is connected to a constrained central system loop. The value of DG in Mississippi is based on its ability to alter power flows consequently reducing congestion in the loop and allowing more production from less expensive units - and to offset expensive central system peak generation. The DG capacity added to the Mississippi system (5.2 MW) is less than the peak loads of the area in which it is installed, and it is installed as a single unit.

While the DG option costs are the same for both studies, and nearly the same amount of total capacity is added in each, the DG solutions are quite different. For the Florida system, smaller amounts of DG capacity are added incrementally as needed to meet peak loads. In Mississippi, one larger DG unit is added to relieve congestion in connected transmission lines and to offset expensive peak generation. Both of these local area solutions are determined in the context of the operation of their overall systems, and based on expected costs throughout the systems.

Because of the site-specific nature of the costs and benefits that are compared to determine the value of DG to a particular system, the specific costs and recommendations of this study cannot be applied directly to other systems. The analysis methodology, however, can be applied to any system for which expected load and system characteristics are available. Spatially-varying marginal costs in any system are an indication of transmission constraints for which DG alternatives may be a solution. DG options should be evaluated

\footnotetext{
${ }^{28}$ These are the optimal DG options if the transmission upgrade cost is greater than the break-even cost; the transmission upgrade is optimal if its costs are less than the break-even costs.
} 
simultaneously with central capacity upgrade options to alleviate transmission constraints, especially if the system has other issues that may increase the value of DG. These issues may include: high-cost peak generation, large transmission losses, environmental concerns, and low reserve margins. If quantifiable, all of these issues can be addressed in an analysis using a model like the EAEM.

The next step in better understanding the role of DGs is to further refine their costs and, in particular, their benefits. Including, for example, tax credits and environmental benefits, would provide a more accurate assessment of the benefits of DG. The accuracy of DG benefits could be further increased with better estimates of avoided central system costs, which would be possible given better representations of loads and transmission system.

Finally, many challenges were encountered in conducting this study. They provide valuable insights for considering new policies and practices that could be considered in a DER strategy. These challenges are summarized in Appendix E. 


\section{APPENDIX A}

\section{MODEL SUMMARY}

The EAEM consists of three models that exchange investment, power demand, and avoided cost information to determine which assets to add - and where and when to add them - to minimize overall expansion costs. ${ }^{29}$ Local investment and production decisions are made by a local mixed integer linear program. Central system investment decisions are made by a linear program, and production costs are estimated by a stochastic multi-area production costing model with Kirchhoff's voltage and current law constraints.

Figure 4 shows the model coordination scheme, which consists of two decompositions. The outer decomposition separates local and central decisions, while the inner decomposition (inside the dotted line in Figure 4) separates central investment from central operation decisions. The inner and outer decompositions are solved and coordinated using generalized Benders decomposition (GBD). ${ }^{30}$ Using GBD, a Benders cut constraint is added to the model formulation at each iteration. For the inner decomposition, the Benders cut constraint represents a Taylor series approximation of the central system cost function around a trial value of central capacity variables, based on their costs and the effects of marginal changes in their values on central system production costs. For the outer decomposition, the Benders cut constraint represents a Taylor series approximation of the total cost function around a trial of the local capacity variables, considering their costs and the effects of marginal changes in their values on the central system.

Figure 4. Coordination of the Three Types of Models

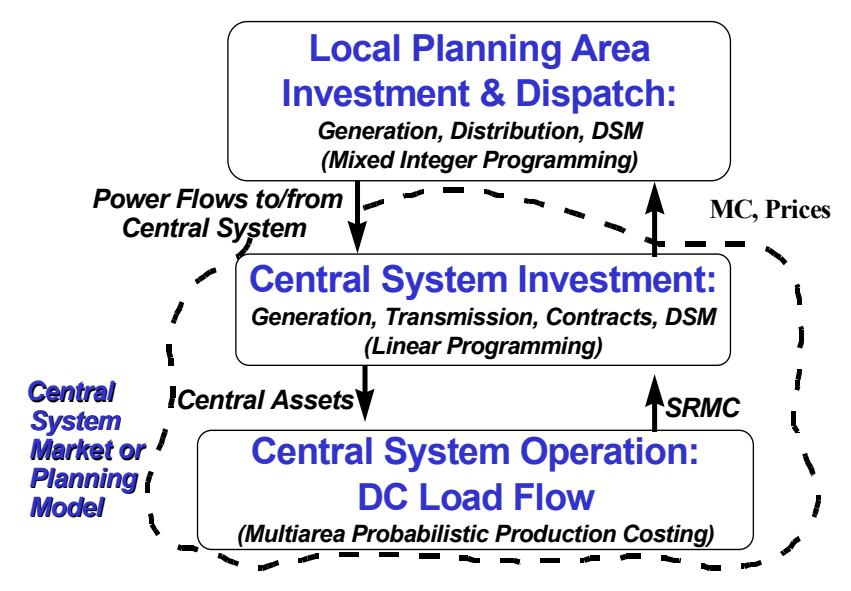

${ }^{29}$ Development of the EAEM was funded by National Science Foundation grant 9696014.

30 See Geoffrion, A.M., "Generalized Benders Decomposition," Journal of Optimization Theory and Applications, vol. 10, no. 4, 1972, pp. 237 - 260. Generalized Benders decomposition is a method for fixing values of "complicating" variables in a separable program and iterating until the variables and the objective function reach their optimal values. According to Geoffrion (pg. 237), complicating variables are those "which, when temporarily fixed, render the remaining optimization problem considerably more tractable." 
In the outer decomposition, the local planning area investment and dispatch model (LPAM) determine transmission flows between the central and local areas. The central system market or planning model $(\mathrm{CSM} / \mathrm{P})$ responds with the total central system costs given these power flows, plus the marginal central system cost at each location in each load period. ${ }^{31}$ This information is used in the Benders' cut constraint of the LPAM to approximate the effect on central system costs of alterations in transmission flows between central and local areas. A Benders' cut constraint is added to the LPAM at each outer decomposition iteration, and iteration between the LPAM and CSM/P continues until convergence (i.e., within a given tolerance) to the minimum overall cost.

The central system investment model (CSI) in the inner decomposition determines central generation and transmission assets. The central system operation model (CSO) responds with the central system operating costs given the assets from the CSI (and the power flows from the LPAM). The CSO also calculates the short-run marginal cost for all generation and transmission assets in each load period. The CSO information is used in the CSI Benders' cut constraint to approximate how central system operating costs would change if generation and transmission assets were altered. Benders' cut constraints are added to the CSI at each inner decomposition iteration; CSI/CSO iteration continues until convergence to the minimum central system cost. At this point, the CSM/P feeds this cost and the marginal central system costs for each location in each load period back to the LPAM.

A unique feature of the Benders coordination scheme used here is that marginal cost information from previous iterations is saved. This method of nested decomposition and coordination guarantees correct marginal costs and model convergence under certain mild conditions that are satisfied by the EAEM models. ${ }^{32}$

\footnotetext{
${ }^{31}$ Because the CSM/P consists of two iterating models (CSO and CSI), calculation of these marginal costs is not straightforward; for details, see McCusker, S.A., A Benders Decomposition Approach to Multiarea Stochastic Distributed Utility Planning, Ph.D. Thesis, Department of Geography and Environmental Engineering, Johns Hopkins University, Baltimore, MD, October 1999.

${ }^{32}$ Ibid.
} 


\section{APPENDIX B}

\section{FEDERAL AND STATE FINANCIAL INCENTIVES AVAILABLE TO DG PROJECTS}

\section{Federal}

The Renewable Energy Production Incentive (REPI) is part of an integrated strategy in the Energy Policy Act of 1992 to promote increases in the generation and utilization of electricity from renewable energy sources and to further the advances of renewable energy technologies. This program, authorized under section 1212 of the Energy Policy Act of 1992, provides financial incentive payments for electricity produced and sold by new qualifying renewable energy generation facilities. Eligible electric production facilities are those owned by State and local government entities (such as municipal utilities) and not-for-profit electric cooperatives that started operations between October 1, 1993 and September 30, 2003. Qualifying facilities are eligible for annual incentive payments of 1.5 cents per kilowatt-hour (1993 dollars and indexed for inflation) for the first ten year period of their operation, subject to the availability of annual appropriations in each Federal fiscal year of operation. Criteria for qualifying facilities and application procedures are contained in the rulemaking for this program. Qualifying facilities must use solar, wind, geothermal (with certain restrictions as contained in the rulemaking), or biomass (except for municipal solid waste combustion) generation technologies.

REPI complements sections 1914 and 1916 of the Energy Policy Act of 1992, which provide tax incentives to certain private sector entities for certain types of new renewable energy generation facilities. The application of these changes to the U.S. Tax Code is administered by the Internal Revenue Service. The REPI program is managed by the Department of Energy. The regulations for the administration of the REPI program are contained in Title 10 to the Code of Federal Regulations, Part 451 (10 CFR 451). The final rulemaking, which contains clarifying supplementary information, is contained in $60 \mathrm{FR}$ 36959 (PDF: $60 \mathrm{~KB}$ ).

The tax incentives available to the private sector for installing renewable energy systems include:

(1) $10 \%$ investment tax credit

(2) $15 \%$ business renewable energy investment tax credit

(3) $40 \%$ residential tax credit

(4) 5-year accelerated depreciation schedule.

\section{Florida specific}

Florida residents, developers, government agencies, utilities, and other businesses installing photovoltaic (PV) systems connected to their local utility may qualify for the Florida Solar Energy Center's (FSEC) PV rebate. The program is funded at $\$ 525,000$ by 
the Florida Energy Office/Department of Community Affairs. The program will continue through March 31, 2002, or until program funds are exhausted.

Rebates of $\$ 4$ per watt are available based on the total system output using the manufacturer or FSEC rating. All systems must have an output of at least $1 \mathrm{~kW}$. Residential applicants can qualify for a maximum rebate of $\$ 16,000$. Additional rebates of $\$ 2,000$ are available to builders and developers installing systems on model homes. Commercial applicants can qualify for a maximum rebate of $\$ 40,000$.

In addition, purchase of PV systems is exempt from the state's $6 \%$ sales tax. 


\section{APPENDIX C}

\section{ASSUMPTIONS AND MODEL CONFIGURATION: MISSISSIPPI}

\section{Assumptions}

The following assumptions are used in the Mississippi analysis:

$\begin{array}{lll}\text { Fuel prices }(\$ / \mathrm{mmBtu}):^{33} & \begin{array}{l}\text { coal } \\ \text { natural gas } \\ \text { oil }\end{array} & \begin{array}{l}\$ 1.48 \\ \$ 4.75 \\ \$ 5.71\end{array} \\ & & 7 \%(\mathrm{real}) \\ \text { Discount rate: } & & \$ 2000 / \mathrm{MWh}^{34} \\ \text { Cost of unserved energy } & & \end{array}$

\section{Model Configuration}

The model is a linear programming model consisting of a cost minimization objective function and the following constraints: load balance for each node, system reserve margin, "loop flow" constraints for voltage loops in the system, and upper bounds on generation and power flow for each generating unit and transmission line, respectively. The model is a version of the EAEM, modified to fit the available data.

Constraints:

Load balance - these constraints state that the load at any bus (minus any unserved load) is met by a combination of generation at the bus plus net power flows into the bus. The model contains one load balance constraint for each bus, in each load period for the study years $(2002-2006)$.

For this study, seven load periods were defined for each year, from $2002-2006$, for a total of 35 load periods. ${ }^{35}$ The sum of the hours in all load periods for one year is 8760 . Each of the buses in the system has a projected load for each load period. The following load data were used to estimate loads for the load balance constraints.

\footnotetext{
${ }^{33}$ The fuel prices are typical for utilities in the state of Mississippi.

${ }^{34}$ The assumed cost of unserved energy is not typical for utilities in the state of Mississippi, and is much higher than the cost used by the utilities in their own planning. The high cost is intended to rule out unserved energy as a viable alternative to DG or T\&D upgrades; market purchases at less than $\$ 1940 / \mathrm{MWh}$ could also reduce expected unserved energy.

${ }^{35}$ EIA load classifications were used to determine which of the 8760 annual hours each load period would contain (Source: "Model Documentation: Electricity Capacity Planning Submodule of the Electricity Market Module," Prepared by: Nuclear and Electricity Analysis Branch, Energy Supply and Conversion Division, Office of Integrated Analysis and Forecasting, Energy Information Administration, March 1994). Load periods have identical durations from year to year (e.g., the peak load period in 2002 contains the same number of hours as the peak load period in 2006).
} 
(1) Hourly system (i.e., all buses) loads for 1999,

(2) Monthly peak bus loads for 1999 ,

(3) Monthly bus energy (kW-hours) values for 1999, and

(4) Monthly projected system peak loads and system energy growth rates for 2002 2006.

The monthly projected peak system load and energy growth rates (4), were applied evenly to the 1999 monthly peak bus loads (2) and 1999 monthly bus energy values (3) to determine monthly bus peaks and energy values for 2002-2006. These values were applied to the 35 load periods described below to estimate the 5285 loads.

To create the load periods, the 8760 system hourly loads for 1999 were separated according to the 22 load segments defined by the EIA. The EIA has nine load group classifications based on month and hours of the day: summer daytime, summer morning/evening, summer night, winter daytime, winter morning/evening, winter night, fall/spring daytime, fall/spring morning/evening, fall/spring night. Within each load group, the EIA methodology then separates loads by magnitude into three load segments (summer daytime, summer evening, winter daytime and winter evening) or two load segments (summer night, winter night, fall/spring daytime, fall/spring morning/evening, fall/spring night). For the groups that are divided into three load segments, the highest $2 \%$ of load represents the Peak, the next $49 \%$ of the load represents Near-Peak, and the lowest $49 \%$ of load in that load group represents Off-Peak. The groups divided into two load segments have a NearPeak segment (highest $50 \%$ of the load) and Off-Peak (lowest $50 \%$ of the load). Thus, the 8760 hourly system loads are divided into 22 load segments, which are then ranked by load magnitude.

After dividing the 1999 loads into the 22 hourly segments, they were applied to the estimated 2002-2006 monthly bus peak loads and energy values to create 22 load segments per year for each bus.

Next, the 22 load segments were aggregated into seven. The segment that included the highest hourly load for the year was designated the peak load period; its length was assigned the number of hours associated with the segment and its magnitude was assigned the highest hourly load in the segment. The segment with the next highest peak load was similarly designated the near-peak load period. The remaining 20 load segments were aggregated into five load periods representing various levels of intermediate and off-peak load.

System reserve margin - there is one system reserve margin constraint for each year 2002 2006 in the study timeframe. These constraints specify a minimum threshold for installed generating capacity plus firm capacity purchases. The threshold is typically specified as the peak system load plus a given percentage above the system peak. A 15 percent reserve margin, typical for most utilities, is used for planning purposes. 
Loop flow - these constraints are the linearized "DC" representation of nonlinear Kirchhoff's voltage law constraints. For each load period, the number of loop flow constraints needed is

$$
\text { \# of transmission lines - \# of buses }+1
$$

The sum over all lines in a loop of \{power flow $\times$ normalized per unit impedance for each line equals zero.

Generating unit limits - unit forced outage rates (FORs) are used to derate the capacity of each unit. In each load period (that a unit is in the system), the upper bound on the unit's production equals its derated capacity. ${ }^{36}$ FORs for the Mississippi units range from $5-20$ percent.

Line power flow limits - The MW line ratings are upper bounds on power flow in either direction on a line. The assumed ratings for the Mississippi system lines range from 30 to $600 \mathrm{MW}$.

Objective function:

Minimize the sum of all NPV production costs, unserved energy costs and new capacity costs for the $2002-2006$ period.

- Each generating unit's production cost for each load period equals its $(\$ / \mathrm{MWh})$ variable operating and maintenance (O\&M) cost plus its $\$ / M W h$ fuel cost, multiplied by the number of hours in the load period. A unit's heat rate $(\mathrm{Btu} / \mathrm{KWh})$ and the cost of fuel $(\$ / \mathrm{mmBtu})$ determine its fuel cost. Variable O\&M costs for the Mississippi generating units range from $\$ 8 / \mathrm{MWh}$ to $\$ 70 / \mathrm{MWh}$ and heat rates range from $10,500 \mathrm{Btu} / \mathrm{kWh}$ for a coal unit to $17,000 \mathrm{Btu} / \mathrm{kWh}$ for an oil unit.

- Unserved energy costs for each load period equal \$1940/MWh multiplied by the number of hours in the load period.

- New capacity costs equal the sum of annualized investment costs through 2006, beginning in the year of the capacity addition. New capacity costs are assumed to be $\$ 450 / \mathrm{kW}$.

\footnotetext{
${ }^{36}$ The generating unit limits in the original EAEM are stochastic; deterministic limits were used in this study because the EAEM requires more plants than the number in the Mississippi system for its stochastic approximations.
} 


\section{APPENDIX D}

\section{ASSUMPTIONS AND MODEL CONFIGURATION: FLORIDA}

\section{Assumptions}

The following assumptions are used in the Florida analysis:

$\begin{array}{lll}\text { Fuel prices }(\$ / \mathrm{mmBtu}):^{37} & \begin{array}{l}\text { coal } \\ \text { natural gas } \\ \text { oil } \\ \text { nuclear }\end{array} & \begin{array}{l}\$ 1.678 \\ \$ 3.863\end{array} \\ & & \$ 5.07 \\ & & 7 \% \text { (real) } \\ \text { Discount rate: } & & \$ 2000 / \mathrm{MWh}^{38}\end{array}$

\section{Model Configuration}

The model is a linear programming model consisting of a cost minimization objective function and the following constraints: load balance for each node and upper bounds on generation for each generating unit. The model is a version of the EAEM, modified to fit the available data.

Constraints:

Load balance - these constraints state that the sum of generation from owned generating units plus generation purchased from other utilities and on the spot market equals the load in each load period for the study period $2002-2006$.

For this study, two load periods were defined for each year, for a total of 10 load periods. This number is less than the seven load periods/year for Mississippi because fewer data were available for the Florida system, and the available Florida data were at a more aggregate level.

The following load data were used to create the 10 load periods:

1) Monthly system peak demands for $2000,{ }^{39}$

2) Total system MWh energy for $2000,{ }^{40}$

\footnotetext{
${ }^{37}$ Fuel prices were provided by the G\&T co-operative.

${ }^{38}$ The assumed cost of unserved energy is not the cost used by the utility.

${ }^{39}$ From "Statistics of the Florida Electric Utility Industry, 2000," Division of Economic Regulation, Florida Public Service Commission, August 2001.

${ }^{40}$ Ibid.
} 
3) System load factor for $2000,{ }^{41}$

4) Projected peak load growth, $2002-2006$, and ${ }^{42}$

5) Projected winter and summer loads for 2002, 2004, and 2006 for the constrained site. $^{43}$

Assuming that the peak load period is twelve percent of a year (1051 hours), the year 2000 annual peak load (1) and the system load factor (3) were used to estimate the year 2000 baseload value. $^{44}$ The total system MWh (2) for 2000 was used as a check on the peak and baseload estimates and the number of hours in the peak and baseload load periods. For years 2002 - 2006, the system peak load growth values (4) to the year 2000 peak load value were applied, and again used the system load factor to estimate baseload values for years $2002-2006$.

Generating unit limits - the unit forced outage rates (FORs) are used to derate the capacity of each unit. ${ }^{45}$ In each load period (that a unit is in the system), the upper bound on the unit's production equals its derated capacity. ${ }^{46}$ FORs for the Florida system range from 3 13 percent.

Objective function:

Minimize the sum of all production costs in each load period from owned generation, purchased energy costs, and unserved energy costs.

- Each generating unit's production cost equals its (\$/MWh) variable operating cost plus its $\$ / M W h$ fuel cost, multiplied by the number of hours in the load period. A unit's heat rate $(\mathrm{Btu} / \mathrm{KWh})$ and the cost of fuel $(\$ / \mathrm{mmBtu})$ determine its fuel cost. Variable O\&M costs for the Florida generating units (for which variable O\&M costs were available) range from $\$ 2 / \mathrm{MWh}$ to $\$ 13.4 / \mathrm{MWh}$ and heat rates range from 9825 $\mathrm{Btu} / \mathrm{kWh}$ to $14,089 \mathrm{Btu} / \mathrm{kWh}$

- Unserved energy costs for each load period equal $\$ 1940 / \mathrm{MW}$ multiplied by the number of hours in the load period.

- Purchased energy costs include a fixed $\$ / \mathrm{kW}$ capacity component that is estimated as a $\$ / M W h$ variable adder, as well as variable operating and fuel costs. These adders range from $\$ 2.7 / \mathrm{MWh}$ to $\$ 12 / \mathrm{MWh}$.

\footnotetext{
${ }^{41}$ Ibid. Load factor is the ratio of average load to peak load.

42 Ibid.

${ }^{43}$ Projected load data were provided by the distribution system.

44 The 1051 hour (twelve percent) peak load period is based on the twelve percent capacity factor of the system's peaking units (personal communication with Florida participant).

${ }^{45}$ The Florida Public Service Commission provided forced outage rates.

${ }^{46}$ As in the Mississippi study, derated generating unit limits were used because the system for which data were available did not have enough plants for the stochastic approximation.
} 


\section{APPENDIX E}

\section{STUDY CHALLENGES}

Nearly 50 people in 24 different utilities, government agencies, cooperative associations, state and national reliability commissions, and state and local public service commissions were contacted to obtain the site-specific information needed for the analysis. Very few showed interest in participating because they claimed that their systems were robust and had no T\&D congestions problems or that the study required data that are not publicly available.

The utilities that eventually agreed to participate were already considering DGs as part of their comprehensive approaches to load management and reliability or were facing constraints in their systems. In addition, the participants saw the study using EAEM as an opportunity to obtain additional analysis that could be factored into decision-making. Despite the fact that neither Florida nor Mississippi has begun to deregulate, due to competitive concerns all participants from both states requested confidentiality.

Data provided by the utilities and/or gathered from public service commissions included system maps, historic load data and projections, transmission line ratings and impedances, generating unit operating characteristics, fuel price assumptions, and power supply contract information. These data were used to create the systems evaluated in each state.

In general, generating unit operating characteristics and aggregate load data are publicly available, but detailed bus-level loads and transmission system characteristics are not. If loads are aggregated or the transmission system cannot be represented due to lack of data, transmission constraints that prevent least-cost dispatch of the generating units and cause marginal cost differences throughout the system cannot be included. In this case, the value of DG options would likely be underestimated. 
Public reporting burden for this collection of information is estimated to average 1 hour per response, including the time for reviewing instructions, searching existing data sources,

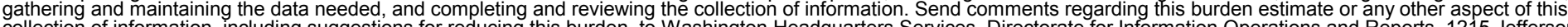

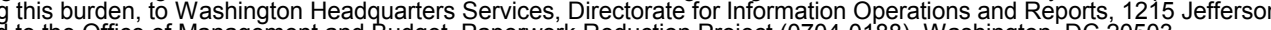
Davis Highway, Suite 1204, Arlington, VA 22202-4302, and to the Office of Management and Budget, Paperwork Reduction Project (0704-0188), Washington, DC 20503.
1. AGENCY USE ONLY (Leave blank)
2. REPORT DATE
March 2002
3. REPORT TYPE AND DATES COVERED
Subcontract Report
January 1999-December 2001

4. TITLE AND SUBTITLE

Value of Distributed Energy Options for Congested Transmission/Distribution Systems

in the Southeastern United States

5. FUNDING NUMBERS

C: KADC-1-31420-01

TA: AS611000

6. AUTHOR(S)

Susan A. McCusker and Jack S. Siegel

7. PERFORMING ORGANIZATION NAME(S) AND ADDRESS(ES)

Energy Resources International, Inc.

$101518^{\text {th }}$ St., N.W., Suite 650

Washington, D.C. 20036

8. PERFORMING ORGANIZATION REPORT NUMBER

ERI-3108.02-0103

9. SPONSORING/MONITORING AGENCY NAME(S) AND ADDRESS(ES)

National Renewable Energy Laboratory

1617 Cole Blvd.

Golden, CO 80401-3393

10. SPONSORING/MONITORING

NREL/TP-620-31620

11. SUPPLEMENTARY NOTES

NREL Technical Monitor: Larry Goldstein

12a. DISTRIBUTION/AVAILABILITY STATEMENT

National Technical Information Service

U.S. Department of Commerce

5285 Port Royal Road

Springfield, VA 22161

13. ABSTRACT (Maximum 200 words)

This report explores the ability of distributed generation (DG) options to provide cost-effective alternatives to central station generation, transmission, and distribution upgrades for alleviating transmission and distribution congestion. The need for this study was driven by three major factors:

1. DOE's DG program, while quite successful in showing the value of DG in large portions of the United States, has been less successful in the Southeast, likely because of the low energy prices, high excess electrical capacity, and lack of electricity deregulation in the region.

2. Lack of DG-related analysis that uses real world data on specific sites that can be used as good indicators of the issues and benefits of DG.

3. Interest on behalf of DOE in analysis in two southern states that can be used to show the value of DG to several key Congressional officials from the states.

To demonstrate this ability for constrained sites in systems in the states of Florida and Mississippi, the Electricity Asset Evaluation Model (EAEM) is used to assess the costs and benefits of installing DG options to reduce load in areas with transmission congestion versus upgrading the transmission and distribution (T\&D) systems.

14. SUBJECT TERMS
distributed generation; DG; Electricity Asset Evaluation Model; EAEM; energy analysis; transmission and distribution; T\&D; Florida; Mississippi; Southeast; distributed energy resources; Energy Resources International; ERI

17. SECURITY CLASSIFICATION OF REPORT

Unclassified
18. SECURITY CLASSIFICATION OF THIS PAGE Unclassified
15. NUMBER OF PAGES

16. PRICE CODE

20. LIMITATION OF ABSTRACT

OF ABSTRACT

Unclassified
UL 